\title{
ВЛИЯНИЕ МЕНСТРУАЛЬНОЙ И РЕПРОДУКТИВНОЙ ФУНКЦИЙ НА РАЗВИТИЕ ПРОЛАПСА ТАЗОВЫХ ОРГАНОВ
}

\section{INFLUENCE OF MENSTRUAL AND REPRODUCTIVE FUNCTIONS ON THE DEVELOPMENT OF PELVIC ORGAN PROLAPSE}

\section{A. Ustyuzhina \\ S. Pakhomov \\ O. Altukhova}

Summary. Pelvic organ prolapse is a common problem in modern healthcare. Despite the fact that the prolapse of the pelvic organs has a long history, until now there is no consensus regarding the etiology and pathogenesis of the disease, and until now, the prolapse of the pelvic organs is considered as a polyetiological disease. Every year all over the world there is an increase in the incidence of genital prolapse in women. Pelvic floor diseases can lead to many adverse consequences in a woman's daily life.

Keywords: pelvic organ prolapse, women, pelvic floor disorders.

\author{
Устюжина Александра Сергеевна \\ Врач акушер-гинеколог, ОГБУз БОКБ Святителя \\ Иоасафа, г. Белгород \\ alexandrashevchenko@yandex.ru \\ Пахомов Сергей Петрович \\ Д.м.н., профессор, НИУ «Белгородский \\ Государственный Университет», г. Белгород \\ pachomw@yandex.ru \\ Алтухова Оксана Борисовна \\ Д.м.н., ОГБУз БОКБ Святителя Иоасафа, г. Белгород \\ kristalinka@yandex.ru
}

Аннотация. Пролапс тазовых органов - распространенная проблема в современном здравоохранении. Несмотря на то, что пролапс тазовых органов имеет давнюю историю, до настоящего момента не сложилось единого мнения относительно этиологии и патогенеза заболевания, и до сих пор пролапс тазовых органов рассматривается как полиэтиологическое заболевание. С каждым годом во всем мире наблюдается рост заболеваемости пролапсом гениталий у женщин. Заболевания тазового дна могут привести к множеству неблагоприятных последствий в повседневной жизни женщины.

Ключевые слова: пролапс тазовых органов, опущение и выпадение матки и стенок влагалища, пролапс гениталий.

изучению влияния травм промежности на пролапс тазовых органов, у группы женщин с глубокой травмой промежности была выявлена более слабая сила мышц тазового дна по сравнению с женщинами с поверхностными травмами [4].

Задачей нашего исследования явилось изучение социально-биологических характеристик, а также особенностей менструальной и репродуктивной функций у женщин с пролапсом тазовых органов. Исследование проводилось в гинекологическом отделении ОГБУЗ БОКБ Святителя Иоасафа г. Белгорода.

Всего было исследовано 135 женщин: 91 женщина с признаками пролапса тазовых органов и 44 женщины без признаков пролапса. Средний возраст женщин, входящих в исследование, составил 62,21土 8,31 год.

Нами были проанализированы социально-биологические характеристики женщин, такие как возраст, весо-ростовой показатель, индекс массы тела (ИМТ), возраст начала половой жизни, число половых партнеров. Женщины, которые вошли в основную груп- 
пу, имели большую массу тела $(75,588 \pm 13,57$ кг) по сравнению с пациентами контрольной группы $(69,04$ $\pm 11,57$ кг, р<0,05), более низкий рост $(162,15 \pm 5,74 \mathrm{~cm}$ и 167,11 $\pm 4,26$ см, p<0,05). При этом ИМТ в основной группе составил 28,75 \pm 4,32, в контрольной группе этот показатель был ниже и составил 24,72 $\pm 3,17$, $\mathrm{p}<0,05$.

Возраст начала половой жизни может указывать на продолжительность периода реализации сексуальной функции. Было установлено, что средний возраст начала половой жизни у женщин основной группы был выше $(20,50 \pm 2,53$ лет, $\mathrm{p}<0,05)$ по сравнению с женщинами контрольной группы $(19,50 \pm 1,66$ лет, $p<0,05)$ на 1 год. Число половых партнеров в течение жизни в обеих группах было одинаково.

Нами были рассмотрены особенности менструальной функции у женщин обеих групп: возраст менархе, продолжительность менструаций и менструального цикла, возраст наступления менопаузы.

Средний возраст менархе у женщин с пролапсом тазовых органов составил 13,9 лет, а у женщин контрольной группы - 13,0 лет $(p<0,05)$. Достоверных отличий в продолжительности менструаций и менструального цикла у представительниц обеих исследуемых групп выявлено не было.

У женщин с признаками пролапса тазовых органов менопауза наступала раньше, чем у здоровых женщин. Возраст наступления менопаузы в основной группе составил 48,92 \pm 3,32 лет, в контрольной группе - 50,48 \pm 4,17 лет, $\mathrm{p}<0,05$.

При изучении репродуктивного анамнеза мы рассматривали следующие показатели: общее количество беременностей, количество медицинских абортов, самопроизвольных выкидышей, замерших беременностей, внематочных беременностей, родов, срок родоразрешения и вес родившихся детей.

Количество беременностей у женщин с признаками пролапса тазовых органов было выше, чем в контрольной группе (5,08 $\pm 2,65$ против 3,31 $\pm 1,70, p<0,05)$.

Среднее число родов у женщин с пролапсом тазовых органов составило 2,06 $\pm 0,98$, в контрольной группе их число было ниже на 0,52-1,54 $\pm 0,76(p<0,05)$. Вес родившихся детей не имел достоверных различий и был сравнительно одинаков $(3672,66 \pm 444,37$ г и 3617,20 \pm 354,80 г).

Обращало на себя внимание большее число абортов на 0,97 у женщин с пролапсом тазовых органов по сравнению с женщинами контрольной группы $(2,62 \pm$ 2,36 против 1,65 $\pm 1,47, \mathrm{p}<0,05)$.

Изучение числа выкидышей в анамнезе показало, что 21,98 \pm 4,34\% женщин основной группы имели один выкидыш, а в контрольной группе - 9,09 \pm 4,33\% $(p<0,05)$; в основной группе $-7,69 \pm 2,79 \%$ два и более выкидыша в течение жизни; при этом в контрольной группе выкидышей зарегистрировано не было.

Среди женщин основной группы у 5,49 $\pm 2,39 \%$ в анамнезе отмечены аномалии родовой деятельности, стремительные роды - у 5,49 $\pm 2,39 \%$, р<0,05, в контрольной группе отягощенное течение родового акта женщинами отмечено не было.

Нами была рассмотрена частота оперативных вмешательств, проводимых в родах, а именно, абдоминального родоразрешения и эпизиотомии.

Частота абдоминального родоразрешения была сравнительно одинакова в обеих группах (у 4,4 $\pm 2,15 \%$ женщин основной и 4,55\% $\pm 3,14$ женщин контрольной группы). В 10,99 $\pm 3,28 \%$ ( $<<0,05)$ случаев у женщин основной группы проводилась эпизиотомия, у здоровых женщин эпизиотомия не выполнялась.

Следующим изучаемым признаком была травматизация родовых путей среди женщин исследованных групп. Установлена высокая частота травматизации родовых путей у женщин с пролапсом тазовых органов. Отсутствие разрывов родовых путей было зафиксировано у 48,35 $\pm 5,24 \%$ женщин, а в контрольной группе у 90,91 $\pm 4,33 \%$ женщин ( $<<0,05)$. Разрывы промежности в предыдущих родах имели место у 23,08 $\pm 4,42 \%$ женщин основной группы и у 4,55 $\pm 3,14 \%$ контрольной группы $(p<0,05)$. Сочетанные разрывы родовых путей в анамнезе имели место у 23,08 $\pm 4,42 \%$ женщин основной группы, в контрольной группе сочетанные разрывы выявлены не были $(p<0,05)$.

Таким образом, было установлено, что женщины с пролапсом тазовых органов характеризовались более высокой массой тела и меньшим ростом, соответственно, более высоким ИМТ. Средний возраст менархе и начала половой жизни у женщин с пролапсом тазовых органов был выше, а менопауза наступала раньше, чем у здоровых женщин. Группа женщин с пролапсом характеризовалась большим количеством беременностей (в том числе абортов и выкидышей) и большим числом родов в течение жизни. Эпизиотомия у женщин основной группы проводилась в 10 раз чаще, чем у женщин группы контроля. По данным нашего исследования, установлена высокая частота травматизации родовых путей у женщин с пролапсом тазовых органов. 


\section{ЛИТЕРАТУРА}

1. Akeel, N.Y. Pelvic floor disorders related to urology and gynecology / N.Y. Akeel, B. Gurland, T. Hull // Fundamentals of Anorectal Surgery / eds.: D.E. Beck, S.R. Steele, S.D. Wexner. - 3 ed. — Cham, 2019. - P. 571-582.

2. Belayneh, T. Pelvic organ prolapse in Northwest Ethiopia: a population-based study / T. Belayneh, A. Gebeyehu, M. Adefris [et al.] // Int. Urogynecol. J.- 2020. — Vol. 31, № 9. — P. 1873-1881.

3. Hallock, J.L. The epidemiology of pelvic floor disorders and childbirth: an update / J.L. Hallock, V.L. Handa // Obstet. Gynecol. Clin. North Am. — 2016. — Vol. 43, № 1. - P. 1-13.

4. Leeman, L. The effect of perineal lacerations on pelvic floor function and anatomy at 6 months postpartum in a prospective cohort of nulliparous women / L. Leeman, R. Rogers, N. Borders [et al.] // Birth. — 2016.—Vol. 43, № 4. - P. 293-302.

5. Maxwell, M. Pelvic floor muscle training for women with pelvic organ prolapse: the PROPEL realist evaluation / M. Maxwell, K. Berry, S. Wane [et al.] // Health Serv. Deliv. Res.— 2020.—Vol. 8, № 47.— URL: https://www.journalslibrary.nihr.ac.uk/hsdr/hsdr08470 (date of the application: 25.02.2021).

6. Milsom, I. The prevalence of urinary incontinence / I. Milsom, M. Gyhagen // Climacteric. — 2019. — Vol. 22, № 3. — P. $217-222$.

7. $\mathrm{Ng}, \mathrm{K}$. An observational follow-up study on pelvic floor disorders to 3-5 years after delivery / K. Ng, R.Y.K. Cheung, L.L. Lee [et al.] // Int. Urogynecol. J. 2017. - Vol. 28, № 9. - P. 1393-1399.

() Устюжина Александра Сергеевна ( alexandrashevchenko@yandex.ru),

Пахомов Сергей Петрович ( pachomw@yandex.ru ), Алтухова Оксана Борисовна ( kristalinka@yandex.ru ).

Журнал «Современная наука: актуальные проблемы теории и практики»

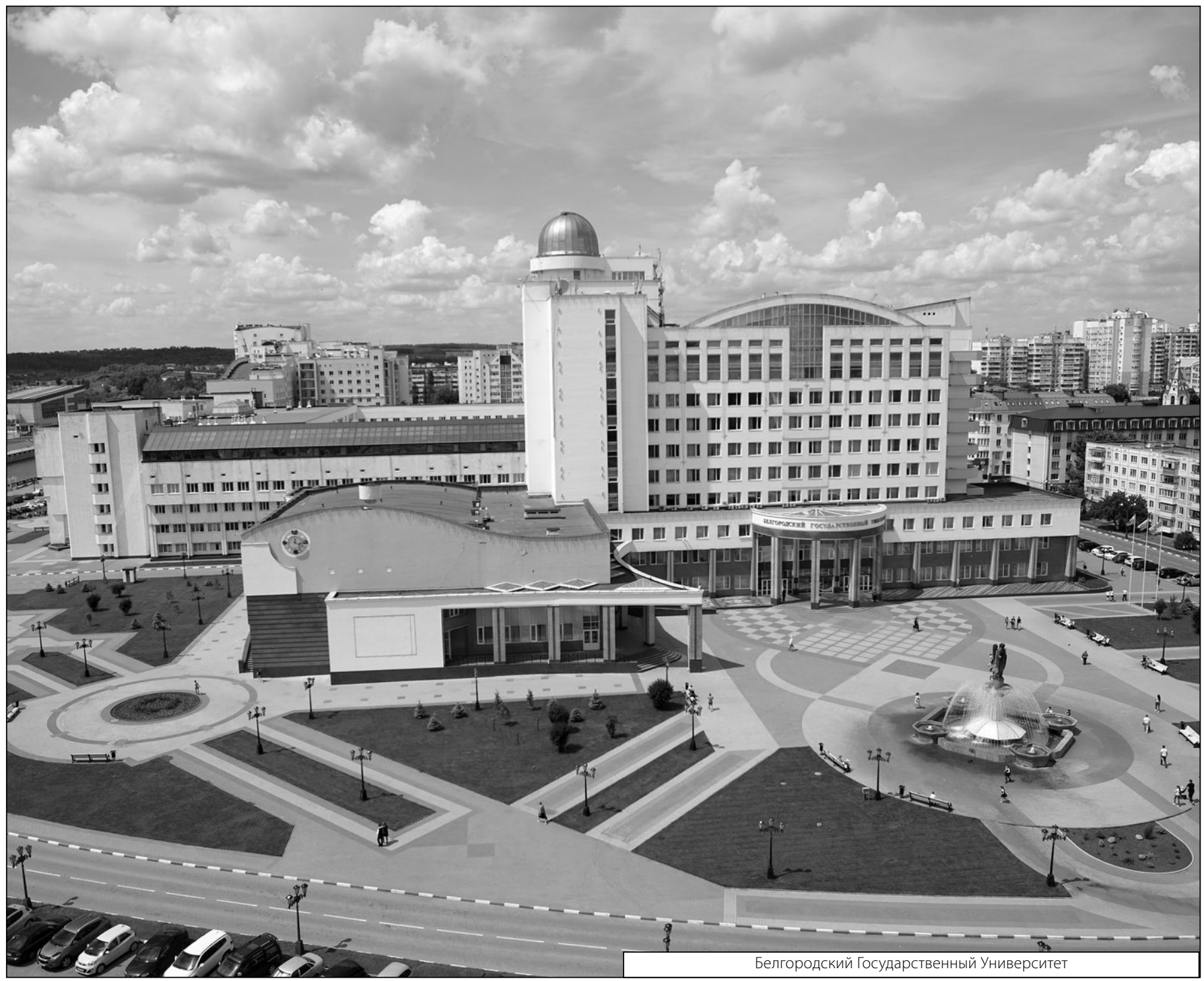

